\title{
A conversation with Huda Zoghbi
}

$\mathbf{H}$ uda Zoghbi is a pediatric neurologist and HHMI investigator at the Baylor College of Medicine and director of the Jan and Dan Duncan Neurological Research Institute at Texas Children's Hospital. She uses genetic and biochemical approaches to explore spinocerebellar ataxia and Rett syndrome. The full video with Zoghbi's stories about fitting in at a historically black medical school and her approach to mentoring can be seen on the JCI website at http://jci.org/videos/cgms.

JCI: Can you tell me a little bit about your childhood?

Zoghbi: I was born and raised in Beirut, Lebanon. My parents were nurturing, loving parents; my dad was a businessman, worked in extraction of olive oil from olives and making soap, and he loved learning. He was a scholar, although he did not pursue an academic career. My mother insisted that we take an academic path.

As a child, I liked the sciences. I always loved biology and math. In high school, I began appreciating literature, both in Arabic and English. In Lebanon, in high school, you can take one of three paths: mathematic, literary/ philosophy, or the biological sciences path. I took the biology path, but decided if I went to college, I was going to major in literature and writing. I was dissuaded from this path by my mother. She kept insisting that since I was good at biology, which she recognized from my childhood, I should really consider medicine. I yielded, not easily, but she persevered, and after a few tears, I decided I would go to medical school.

JCI: You found yourself in medical school in Beirut in 1976, during a civil war.

Zoghbi: We were a class of 63 students and had to make a decision whether to stay and finish the year or disperse and go home. We made the decision to stay, but those who did not live on campus had to find safe places to stay. I lived in a bathroom - it was a closed room within the bathroom, and I had put a sleeping bag on the floor. Once we made the decision, our life became going to school and at night staying together in a safe place avoiding the bombs falling all around us. Just before the year was over, my younger brother was injured when shrapnel hit him. My parents were very upset, so the plan was for us to leave for the summer when the school year ended. The airport was closed, so we had to go via Syria by car. Then from

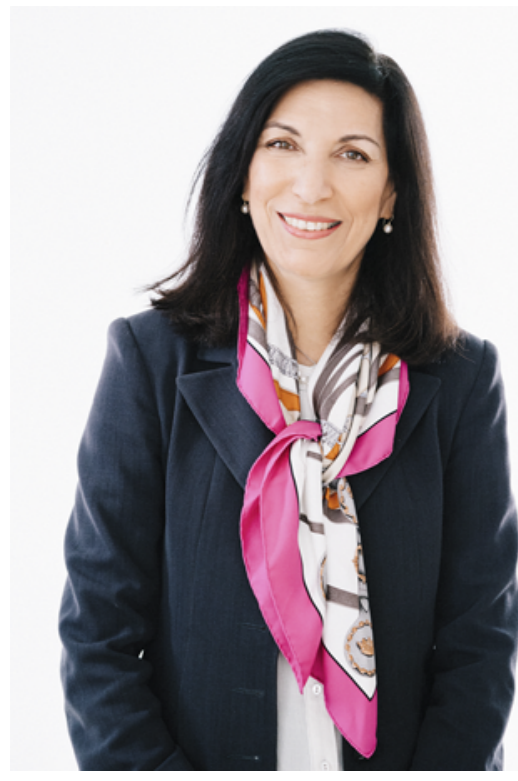

Figure 1. Huda Zoghbi on November 18, 2015. Image credit: Alexey Levchenko.

Syria to Europe, where we met up with my uncle, and after a few days to my sister, living in Austin, Texas. I left hoping that it would just be a month or two and that people would come to their senses and the war would be over.

I stayed with my sister through the summer hoping every day that things would get better so that I could return to medical school. Things in Lebanon actually got much worse. I didn't know medical school in the US starts in August; in Lebanon, it started in October. I had no options in Austin, and it was hard to find a medical school that would consider me so late in the game. A friend of the family in Nashville invited me to spend the weekend, and he had a friend who worked for the Hospital Corporation of America. His friend advised me to try Vanderbilt, but they wouldn't take a transfer student, especially not two months late. But they recommended Meharry Medical College. They were intrigued by my background and said, "School started two months ago, but we'll take you." I was really shocked and flabbergasted that I was accepted on the spot.

JCI: When did you decide on pursuing pediatrics?

Zoghbi: I spent my fourth year at various medical schools - Stanford, Emory, and Baylor - taking electives. During my visit to Baylor on the pediatric cardiology rotation, I decided to do my residency there.

As a pediatric resident, you have to rotate on many different subspecialties, and I rotated with neurology. I remember vividly on rounds, we had a lot of cardiac patients with neurological problems, and though I was fascinated by the heart, Marvin Fishman, who had just arrived from Wash $U$ as the new chief of pediatric neurology, would say, "Why do we always focus on that stupid organ? Let's talk about the brain." He convinced me that the brain is far more interesting. I loved how from the history, you try to solve the puzzle and gradually fine-tune it. We would take pride in coming up with the diagnosis with a minimal number of tests.

During that period, I started feeling the unfairness of that specialty; this was the early 80 s, when we were seeing children with devastating neurological disorders and you had to tell the parents, "We don't know the cause, but think it's genetic. There is a one in two to four chance it will happen again, but we really can't help you."

I approached Arthur Beaudet to get training in genetics. I wanted to work on Rett syndrome, as by then I had seen tens of patients and I was convinced it was genetic because they were all girls. I started logging them in to collect blood to one day find the gene responsible for Rett syndrome. He said, "There are all these individual cases; they are all one in each family. You can't go after a gene when there is no map." He kindly offered me any project in his lab. I was interested in dominant neurodegenerative diseases. There was a family in Texas that 
had a dominantly inherited balance disorder, spinocerebellar ataxia, and Art was aware of that family from the genetics clinic, so we decided I would clone its gene (SCA1) and in the process learn molecular biology.

JCI: Where along this process did you start collaborating with Harry Orr?

Zoghbi: My collaboration with Harry is one of the highlights of my scientific career. I found a paper about a family in Minnesota that had been mapped to be $S C A 1$, and I heard that Harry Orr was working on it. My first reaction: petrified. Here's this established scientist, unlike me who's barely learning her way around the lab. He's already working on SCA1, and how would I catch up with him? I figured, he had a family to study, I had a family, we'll both see where that will get us.

Back then, there were not many DNA markers and David Cox had developed a technology called radiation hybrids, and David was kind enough to teach me how to do it successfully. I created a bunch of resources for chromosome 6 [Orr had already narrowed the region to chromosome 6]. I called Harry and told him, "I think my family maps differently than yours, so here are these hybrids if you'd like them." For a while, he worked on his own region and I worked on mine. But it bugged me that the same disease mapped to two different regions of the chromosome, and that's when I did some detective work and discovered that in my family, the disease had not come solely through the bloodline, but came also from a spouse who died before ever being affected. Once I put that in, it became clear that my gene mapped on top of Harry's gene. I called Harry and told him the story and his first reaction was, "Do you want your hybrids back?" And I said, "No, but I think now we can collaborate! Now we are both working on the same gene!" He calls this "the call"; I will never forget the silence for about 10-15 seconds. And he said, "Let's do it." And we did. We published our first two papers back to back.

Later, Tom Caskey, who was then the chair of the genetics department, gave a seminar where he described the discovery of the myotonic dystrophy gene as a triplet repeat expansion. I was sitting there hearing the description of how in the mother the repeat is smaller; in the child it's really big, with the child having a much more prominent clinical phenotype than the mother. That was exactly what happened in my Texas SCA1 family, generation after generation. The disease kept happening earlier. My youngest generation had a 4- and 10-year-old affected. I became convinced that it had to be a triplet repeat, just like myotonic dystrophy. We stopped everything else to look for triplet repeats; we made all alleles for every potential combination of the sequences. I called Harry to tell him I thought it would be a triplet repeat. The region we had narrowed it to was a million base pairs; he was to take one half and I the other. We shared the oligos and started marching down both ends. On the same day, April 8th, 1993, we both discovered the gene right in the middle where we had 70 kilobases of overlap. He was sending me a fax of the expansion in his family, and I was sending him a fax of the expansion detected in our family. Both figures made it into that first paper. Our collaboration is ongoing, and excitingly, we've identified a therapeutic target that you can pharmaceutically inhibit and that modifies disease symptoms in our models.

JCI: All the while, you're not able to get Rett syndrome out of your mind.

Zoghbi: I was always trying to find ways to get me closer to one day maybe finding the gene, and the only way was to keep collecting more individuals. By the time I had started my own lab, I had samples from over 200 girls, all the while searching for a rare individual with either chromosomal abnormality or a translocation where maybe the gene could be or perhaps familial cases those were extremely rare. I had this family where second cousins both had Rett, but they shared nothing as far as their genome on the X chromosome with their parents.

Any logical person would have quit, so why didn't I? I think it was the clinical picture. It was so consistent that only an underlying genetic defect could give you the classical features of Rett syndrome where you start off being a normal baby for a year to 18 months, and then you gradually lose language and begin hand wringing. You never see that prototypical hand wringing except in Rett syndrome, along with the inability to move swiftly, the tremors, the hyperventilation.

Secondly, there are two types of disorders: those that are developmental - the brain is abnormal at birth - or those that are degenerative, where the child is born normal, but with time, you see cell loss in the brain, atrophy, and massive degeneration. Rett did not fit either. Babies are born normal; they lost milestones, but had no degeneration. I wanted to know why. There were papers published saying it was not an $\mathrm{X}$-linked disorder. My grants were rejected because people thought it would be impossible to find a sporadic disease gene.

JCI: You were returning from Lebanon. You hear your phone ringing as you've got the key in the door, and it's your postdoc saying she found the genetic mutation.

Zoghbi: I got home around 4:30, and the phone was ringing. I said, "How long have you been calling?" She said, "Constantly." I asked her to bring her notebooks and looked at the data, and I just had chills down my spine. I couldn't believe it because I'd had so many red herrings after 16 years, it was tough to believe. But we saw in patient after patient that there was a null mutation in MeCP2 [methyl-CpG binding protein 2] that was inactivating. We didn't see it in the parents, so we knew right away this must be it.

We know MeCP2 binds methylated DNA; we know that it is a methyl cytosinebinding protein. It's important for almost every cell in the brain, and that orchestrates the levels of genes in the brain. Since it's essential for the normal function of every brain cell, this is why when you have a mutation in half of the brain cells, you have dysfunction of every part of the brain. We know that you need it all the time. Two labs have also found that if you bring it back, you can correct some of the symptoms.

We also know the brain is extremely sensitive to its levels. We created an animal model with twice as much MeCP2, resulting in a devastating neurological syndrome. You lose it, it's bad; when you have an extra copy of it, it's bad; if you have more copies, it's even worse.

JCI: If you had to do it all over again and you couldn't be a scientist or clinician, what do you think might have motivated you to be quite as persistent and tenacious?

Zoghbi: I like to solve problems. I think I would probably try to figure a way to solve some problem. I can't tell you in which domain, but it could be politics, as I would love to find a way to turn things around and motivate people through hope and education.

\section{Ushma S. Neill}

